\title{
IMPROVE THE OPERATING PERFORMANCE OF SEA WATER SYSTEM IN MED/TCD UNIT IN EGYPT
}

\section{USINGSIX SIGMA METHOD}

Donia, Noha, S. ${ }^{(1)}$; Nagla, T. F..$^{(2)}$ and Kaka, A. A. ${ }^{(2)}$

1) Institute of Environmental Studies and Research, Ain Shams University

2) Nuclear Power Plants Authority

\begin{abstract}
The purpose of this paper is to establish a maintenance program for the sea water System as a critical part from Desalination Unit type (MED/TCD), to satisfy all requirements needed as the main supplier for most of the systems in the desalination unit, improve the performance of desalination unit, and increase the life time of its components.

The methodology/approach - by applying the scientific method (four step method) plus the PDCA cycle, it means we apply the Six Sigma philosophy. To improve the performance of the multi effects Desalination unit and increase the operational lifetime, we will work on one of the critical system in the MED/TCD unit (Sea Water System SWS) establishing maintenance program using the Six Sigma philosophy, define, measure, analyze, improve, and control (DMAIC) method for problem-solving methodology in MED/TCD Unit, to increase the Reliability and Availability of the MED/TCD Unit and increase the unit lifetime.

Keywords: Six Sigma, Multi Effect Desalination, Sea Water System, Reliability Centered Maintenance, Plan-Do-Check-Act Cycle, Reliability, Availability.

Abbreviations:-

SWS Sea Water System.

PDCA plan - Do - Check - Act Cycle.

MED Multi Effect Desalination.

MED/TCD Multi Effect Desalination/ Thermo-compression Desalination.

DMAIC Define - Measure - Analysis - Improve - Control Cycle.

RCM Reliability Centered Maintenance.

PMP Preventive Maintenance Program.
\end{abstract}




$\begin{array}{ll}\text { IMS } & \text { Integrated Management System. } \\ \text { DPMO } & \text { Defects Per Million Opportunity. } \\ \text { DOE } & \text { Design Of Experiment . } \\ \text { DFSS } & \text { Design For Six Sigma. } \\ \text { PHE } & \text { Plate Heat Exchanger. } \\ \text { SIPOC } & \text { Supplier, Inputs, Process, Outputs, and Customers . } \\ \text { CTQ } & \text { Critical To Quality. } \\ \text { ANOVA } & \text { Analysis Of Varience. } \\ \text { DPU } & \text { Defects Per Unit. } \\ \text { RCMP } & \text { Reliability Centered Maintenance Program. }\end{array}$

\section{INTRODUCTION}

Using six sigma method means applying the four-step method, Observe, Hypothesis, Data collection and Conclusion plus the PDCA cycle, Plan, Do, Check, Act methods to enhance the Maintenance program that matches with the Six Sigma methodology, so we will use the Reliability Centered Maintenance (RCM) instead of the Preventive Maintenance Program (PMP). The Integrated Management System (IMS) approach instead of the Quality Management System and also the Leadership Principle shall apply. Six Sigma is a project-based, customer-focused, and data-driven approach [Coronado, R.B. and Antony, J. (2002) and Black, K. and Revere, L. (2006)] that makes use of a structured and systematic methodology, which relies on the define, measure, analyze, improve, control (DMAIC) roadmap for continuous improvement, to enhance the capability of business processes [Goldstein, M. (2001), Senapati, N.R. (2004)]. To be effectively implemented, this problem-solving methodology requires full management belief and commitment, a well-trained and experienced technical project leadership to act as a change- agent, and a dedicated and competent 
multifunctional project team [Coronado, R.B. and Antony, J. (2002), Robert G. Launsby, Mark J. Kiemele Stephen R].The aim of this paper is establish a maintenance program for the one of the critical system in the MED/TCD desalination plants (Sea Water System) to achieves the six sigma strategy, this maintenance program named Reliability Centered Maintenance (RCM). The Importance of this system is to adjust and control the Sea Water Parameters like the sea water pressure, temperature, flowrate, and impurities for feeding the other systems like the chemical dosing system, brine rejection system, distillate water system, and evaporation system. The project was identified and selected to enhance the current Performance, the Availability, and the Reliability of the desalination unit to increase the lifetime of the other systems and components. This paper is divided into seven sections. In Section 2, an overview of six sigma is given. The status and behavior of the Sea Water System before applying the six-sigma methodology will have provided in Section 3. Establishing Integrated Quality Assurance Program for the maintenance of the Sea Water Systems is presented and described throughout Section 4, the Analyze phase of six sigma will have provided in section 5, the Improvements and Control phase will have provided in section 6, as well as the discussion of its results and practical implications. Finally, the conclusions are summarized in Section 7. 
J. Environ. Sci.

Institute of Environmental Studies and Research - Ain Shams University

\section{METHODOLOGY}

Six Sigma has been applied to many companies that have a productivity with great success and has been subsequently transformed into the strategic management system of these companies Six Sigma was developed at Motorola/USA in 1987 by Bill Smith (Arnheiter and Maleyeff, 2005) and was enhanced by GE after 1995 (Slater, 1999). It was intended to reduce variability and waste in operational processes that were based primarily on statistical process control and total quality control/TQM [Issa Bass Barbara Lawton, Ph.D] Six Sigma is a methodology that can be defined both in statistical and business terms. In statistical terms, Six Sigma refers to 3.4 defects per million opportunities (DPMO) in a given production process. Sigma $(\sigma)$ is used to represent the variation (standard deviation) of a process mean. In business terms, Six Sigma is a strategy used to improve business profitability by eliminating waste, reducing costs from poor quality management and improving the effectiveness and efficiency of all operations to meet or exceed customers' requirements and expectations [Kai Yang, (2005)]. There have evolved two key methods for carrying out Six Sigma. The first method is the most well-defined and works best if you have a problem with an unknown solution in existing products, processes or services. This method is called DMAIC phases. Each of these processes (phases) can be realized with different tools and techniques while some tools can be used in more than one processes (phases). One possible use of technique in the Six Sigma methodology for an improvement process is design of experiments (DOE).The newest method, which is in the developing stages, is called 
Design for Six Sigma or DFSS. The goal of DFSS is to develop a new product, process or service that is defect-free in the eyes of the customer. The main steps for developing the six sigma projects are the following:

- Identification of Six Sigma projects;

- Selection of Six Sigma projects;

- Six Sigma project planning;

- Six Sigma project execution and completion; and

- Post Six Sigma project, where lessons learned are determined, recorded, and archived.

Status and behavior of the sea water system before applying the six sigma strategy:

The behavior of the Sea Water System will be provided in fig (1), fig (2), fig (3), fig (4), fig (5) and fig (6) for the Sea Water (The main Components of MED/TCD Desalination Unit including the SWS. Pump flowrate, temperature, PHE Inlet pressure, PHE Outlet pressure and Water Conductivity) respectively. The Sea Water System composed of four parts as follows:

- Brine Plate Heat Exchangers (PHE) system. The temperature of brine water that rejected from the evaporation system shall be cooled before entering again to the system or rejected to the Sea. For cooling the brine water, we use sea water.

- Distillate Plate Heat Exchangers (PHE) system. The temperature of distillate water that produces from the evaporation system shall be cooled before storage. For cooling the distillate water, we use the sea water. The data of the PHE and sea water during the operation is provided in fig (4), 
fig (5), and fig (6) for the PHE (inlet pressure, outlet pressure, and Sea Water Conductivity) respectively; and

- Condensation system for cooling the distillation water before entering the PHE system, to raise the pressure it is pumped and stored as a final product. the data of the condensation system during the operation is provided at fig (7), and fig (11) for condenser (inlet temperature, and Condenser vapor temperature) respectively.

- Pre-heater system. This system used to increase entering sea water temperature, if needed especially in the winter season, before entering to the evaporator system. The data of the pre-heater system will be provided in figure (8), fig (9), and fig (10) for the Sea Water Pre-heater Inlet Temperature for the three stages of preheating respectively. The Pareto charts for these systems is provided in fig (12), fig (13), and fig (14) for (Brine PHE, Distillate PHE, and condensation) systems respectively.

\section{Integrated quality assurance program for SWS maintenance:}

Project planning: The Planning phase is the first stage that takes place before the DMAIC roadmap is initiated. It intends to reach understanding the problem in chemical dosing systems, and ends with the project planning tasks. For the chemical dosing Systems, it composed of the tow components (Tank for storage the chemicals, and pump for pumping the Sea water with mixing the chemical before entering to the evaporator systems. The Operating data tell us the variations of each component of the system. 
Definition phase: The initial efforts of this phase targeted a deep understanding of the system operation and maintenance. Process mapping tasks using a supplier, inputs, process, outputs, customers (SIPOC) diagram, depicted in table 1, were carried out. then gathered and analyzed data from the operation and maitainence process, by inspecting the components of each system for the Chemical dosing system in the MED/TCD PLANT. At the same time, an affinity diagram was constructed to group similar types of defects into a same class/category of defect. The last activity of this DMAIC phase was the setting of critical to quality (CTQ) characteristics and of their operational definitions, which in this case is a clear, unambiguous, and observable standard of acceptance. For each group of defects, a document with a similar structure to the one exhibited in Figure 4 was developed to characterize each CTQ and to establish its correspondent operational definition.

Measurements phase: Operation results were recorded to assess the baseline performance of the chemical dosing system in the operation. In these records, all key controllable input variables remained constant, at the levels usually used in the normal operation at full load (100\% of load). The measures were taken during 9 months every 2 hours. A total of 1024 measured data were recorded, and 860 of them were far away from the average measured in figures 8,9, and 10 for anti-foam system, figures 2,3 and 4 for anti-scale system, and figures 5,6 and 7 for de-chlorination system; thus, the resulting proportion of deviation from the average was around 83.9 percent, which is a very high value. After categorization the variations from normal operations as 
a percentage values, now we can calculate the Defect Per Million Opportunity (DPMO) by the following equation:

$\mathrm{DPMO}=\frac{D}{P \times 0} \times 10^{6}=\frac{9004}{82980} \times 10^{6}=108,508$

Where, D: is the total number of measurements that deviated from the normal values; P: the total number of measurements for the Sea Water Systems; and O: the considered number of opportunities for deviation of the measures.

The number of opportunities for measures variation comprises the six categories of variations from sigma table the DPMO, the corresponding Sigma level $(Z)$ value is approximately 1.61 equivalent to $2.73(\sigma)$ sigma level.

Analysis phase: The first activity of this phase was the development of an interrelationship digraph, illustrated in Figure (15), to study and understand the chain of causes-and-effects that will ultimately create the different types of defects in the Sea Water System operation.

Determination of the significant factors that contribute to the most relevant types of deviations from normal operation of the Sea Water System. A critical observation of the output variables using (DOE) should thus allow the team to isolate the factors that influence the variability of the normal operation of the dosing system. To carry out the DOE in the analyze phase, the following sequence was adopted:

- selection of the response variables;

- choice of the controllable factors (input variables);

- preparation of the DOE; 
- conduction of the DOE;

- analysis of the results; and

- identification of possible interactions.

Selection of the response variables. A DOE strategy was developed in order to investigate which controllable input factors of the Sea Water System have a significant effect on the CTQ characteristics of the Sea Water system operation. Three specific CTQs were considered:

- preheater malfunction (CTQ1);

- temperature sensing (CTQ2); and

- PHE pump pressure (CTQ3).

The variables inherent to these three CTQs are not continuous. Choice of the controllable factors. Using the information from the interrelationship diagram, the audit of the production process was held to identify which factors could have an effect on the CTQs (output variables). the following five controllable input factors:

- Malfunction of measured temp;

- Failure of the sensing level;

- Operator of the desalination unit have a lack of training;

- Not maintained equipment; and

- Not calibrated devices.

To investigate their individual and combined influence on the CTQs, two distinct levels were defined for each process, as shown in Table II. Preparation of the DOE. To avoid running all the 32 possible combinations among the levels of the five factors, corresponding to a 25-full factorial, a two-level fractional factorial strategy was designed. In particular, a 25-1 
experimental design was defined, thus only half of the 32 treatments needed to be considered. In this resolution of table II design, single factors are not aliased with two-factor interactions, but some two-factor interactions are aliased with other two-factor interactions [David M. Levine., (2006),NJ: Prentice Hall, (2001)]. To estimate the measurement error, each combination was replicated two times. Furthermore, it was decided that for each replicate, a total of 1024 measures were taken and then analyzed. The experimental design strategy is exhibited in Table III. The measurement results in terms of proportion of deviations for the three CTQs are shown in Table IV. Proportions follow normal distribution as shown in figure (16). The linear model, namely a logistic regression model, could have been used to work with the original binary data. Because the sample sizes are different, so data were analyzed using the general linear model of the analysis of variance (ANOVA) [Kai Yang,(2005), Forrest w. Breyfogle, (1999), and D.H. Stamatis, (2003)]. Analysis of the results, including the identification of possible interactions. The resulting ANOVA tables for the three CTQs are shown in Table $\mathrm{V}$. The $\mathrm{R}^{2}$ values ensure that the factors and interactions explain about 70 percent of the total variation observed on the output of this operation, regarding the mentioned CTQs. A confidence level of 95 percent was utilized (i.e. a significance level of 5 percent). The significant factors and interactions are those whose p-value is below the significance level of 0.05 . Despite not being statistically significant, some factors and interactions were considered important by the project team because their p-value is relatively small. 
Coefficient of determination $\mathrm{R}^{2}$ : The coefficient of determination in a DOE measures proportion in the total variation that is due to the model. It is therefore the ratio of the sum of squares of the model to the total sum of squares. The $\mathrm{R}^{2}$ values ensure that the factors and interactions explain about 57 percent of the total variation observed on the output of this operation, regarding the mentioned CTQs. A confidence level of 95 percent was utilized (i.e. a significance level of 5 percent). The significant factors and interactions are those whose $\mathrm{p}$-value is above the significance level of 0.05 . Despite not being statistically significant, some factors and interactions were considered important. Experimental data from the DOE enabled us to compute a set of important metrics. Table VI summarizes the values for the rate of variations of the parameters due to operation, the average number of variations per operation (defects per unit (DPU)), and the Sigma Level.

Determination of the root causes for the occurrence of the abnormalities in the Sea Water system operation. In addition to equipment maintenance, devices calibration, feeding channels, maintenance procedures, and sensing levels, when Monitoring occurs during the unit operation, many of them had structural abnormalities, such as failures. Structural abnormalities tend to appear when the unit work for long time from the scheduled maintenance after of the unit maintenance.

To investigate the influence of maintenance and calibration in the performance, and quality of the Sea Water System unit operation, some samples of measuring data containing structural abnormalities were taken for analysis. The results of the data measured found that some abnormalities in the Sea Water System output when the Critical components to quality not 
maintained like (the PHE pump, PHE sensors, pipes cleaning from solid waste). After some auditing we discovered that wrong procedures for the maintenance of the Sea Water System was carried out.

Improve \& control phase: After having determined the root causes for the high variations rate of the parameters for the Sea Water System in the Measure phase of the DMAIC approach, the development procedure of improvement actions to be implemented for the Sea Water System. A set of procedures established, including the operator's procedures, was undertaken. Many ideas of improvement actions were collected, combined, analyzed, and the most promising ones considered. The final version of the improvement plan contained a set of actions that were grouped around the four areas indicated in Figure (17). In this figure, the area of action 1 - Establishing Reliability Centered Maintenance Program (RCMP). The main effect on the operation of the Sea Water System is the lake of a maintenance program that determine the critical components in the system and establish the maintenance program for this systems to enhance the operation parameters. From the analyzed data in the previous section we found that the critical components in the system are the following:

- BHE pumps,

- main control valve,

- BHE Sensors for measuring water and steam temperature, and

- main pipes connected between the seawater and the chemical dosing system. 
For the three types of variations assessed in the DOE, and according to the conclusions that were described in Table VI, the maintenance program will follow the reliability centered maintenance (RCM). The main principles of the RCM are to define the critical components of the system and developed the maintenance program to achieve the operation requirements. After developing the RCMP for the Sea Water System, the system data will provided in the figures $(18,19$ and 20$)$ the average value for the three Sea Water System systems for the measured parameters (Condenser inlet temperature, PHE flowrate, and PHE pressure) respectively.

\section{RESULTS AND DISCUSSIONS}

The main components behavior of Sea Water System as follow:

Status and behavior of the sea water system before applying the six sigma strategy

The wetland ecosystem is affected by several socio-economic drivers resulting 
J. Environ. Sci.

Institute of Environmental Studies and Research - Ain Shams University

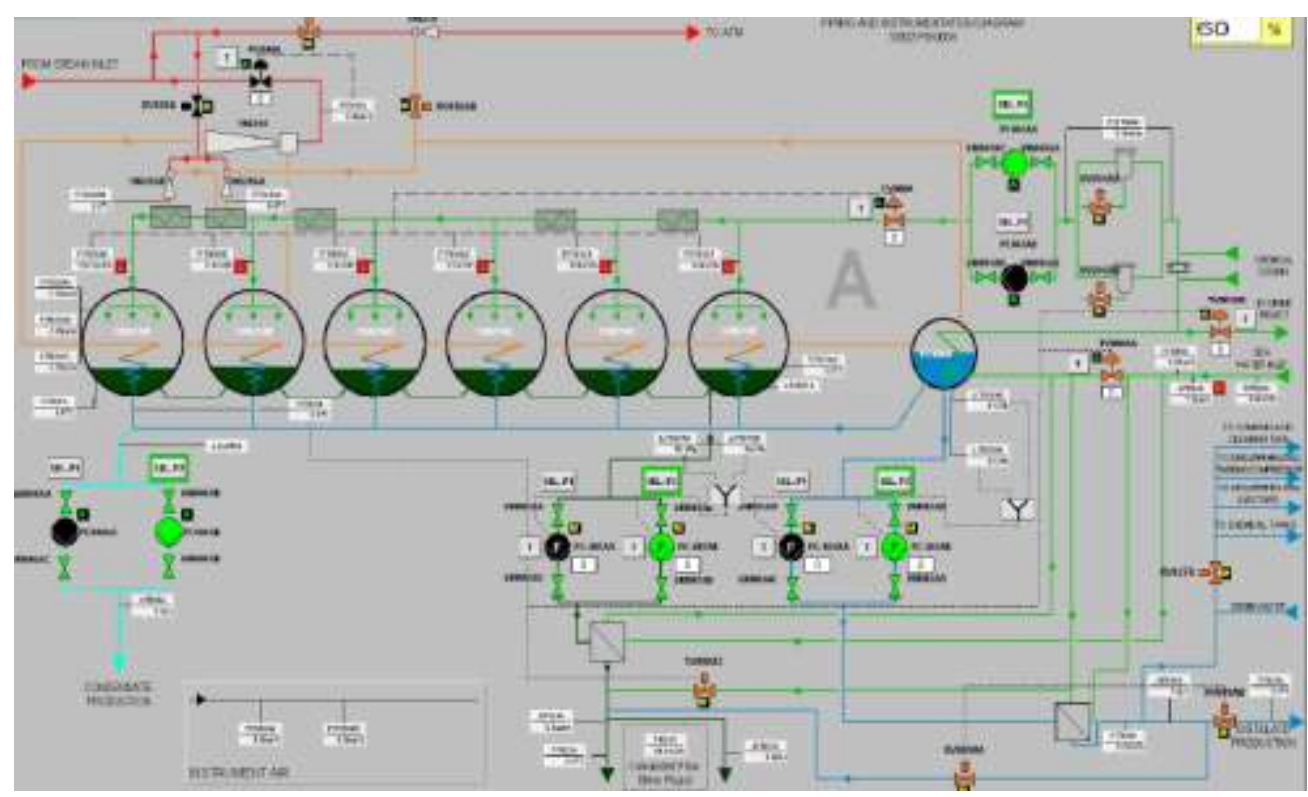

Fig.(1): MED/TCD Desalination Plant Components

\section{$\mathrm{X} \mathrm{m} 3 / \mathrm{h} \cdot{ }^{\circ} \mathrm{C}$}

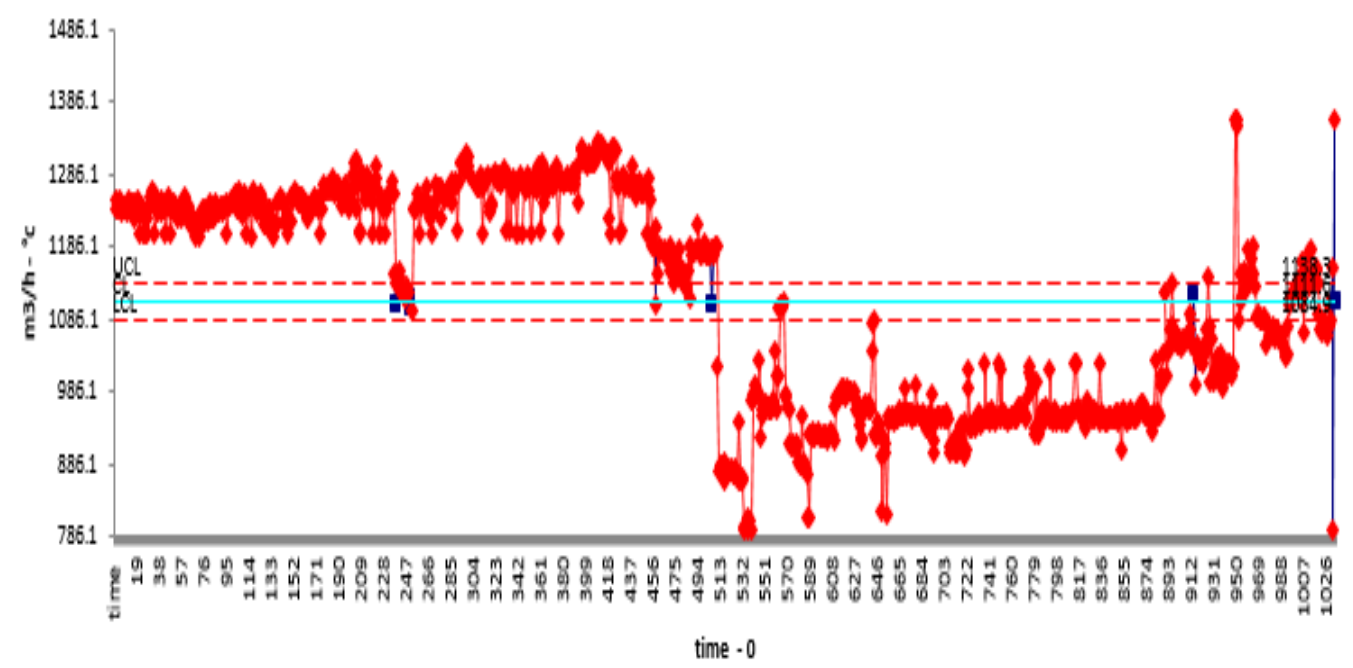

Fig (2): Sea Water Flowrate 




Fig (3): Sea Water Temperature

X PHE inlet pressure

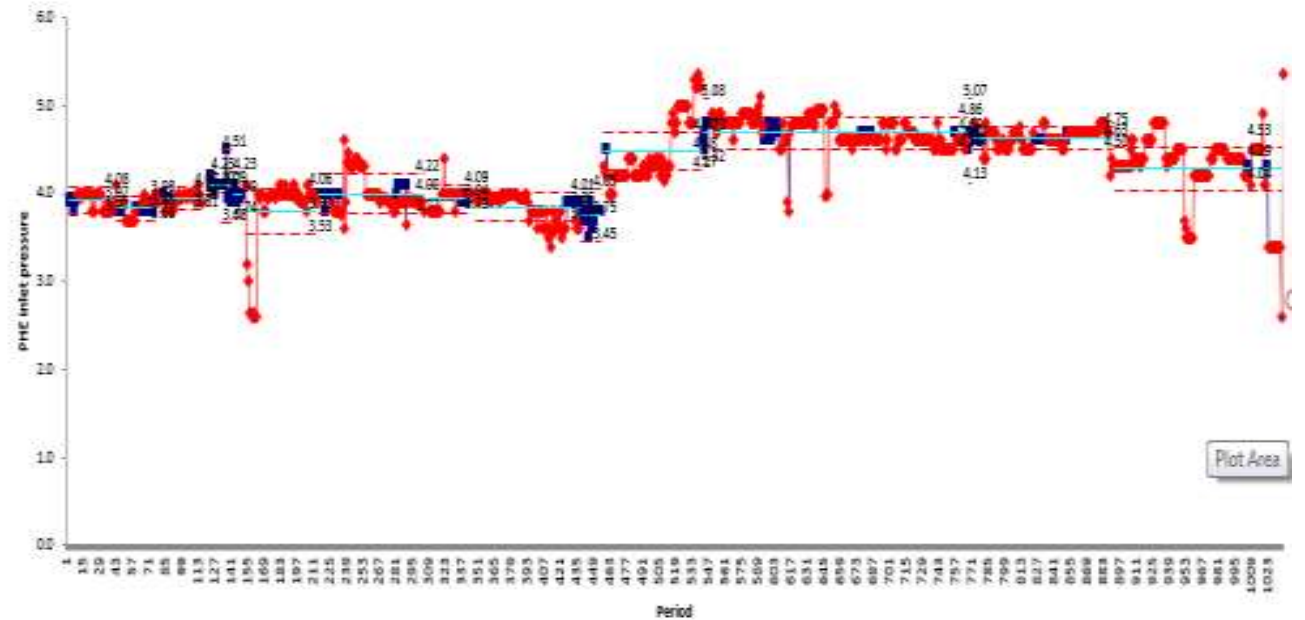

Fig (4): PHE Inlet Pressure 
For PHE system, the following distribution for the inlet pressure, outlet pressure, and Sea Water Conductivity.

\section{PHE Outlet pressure}

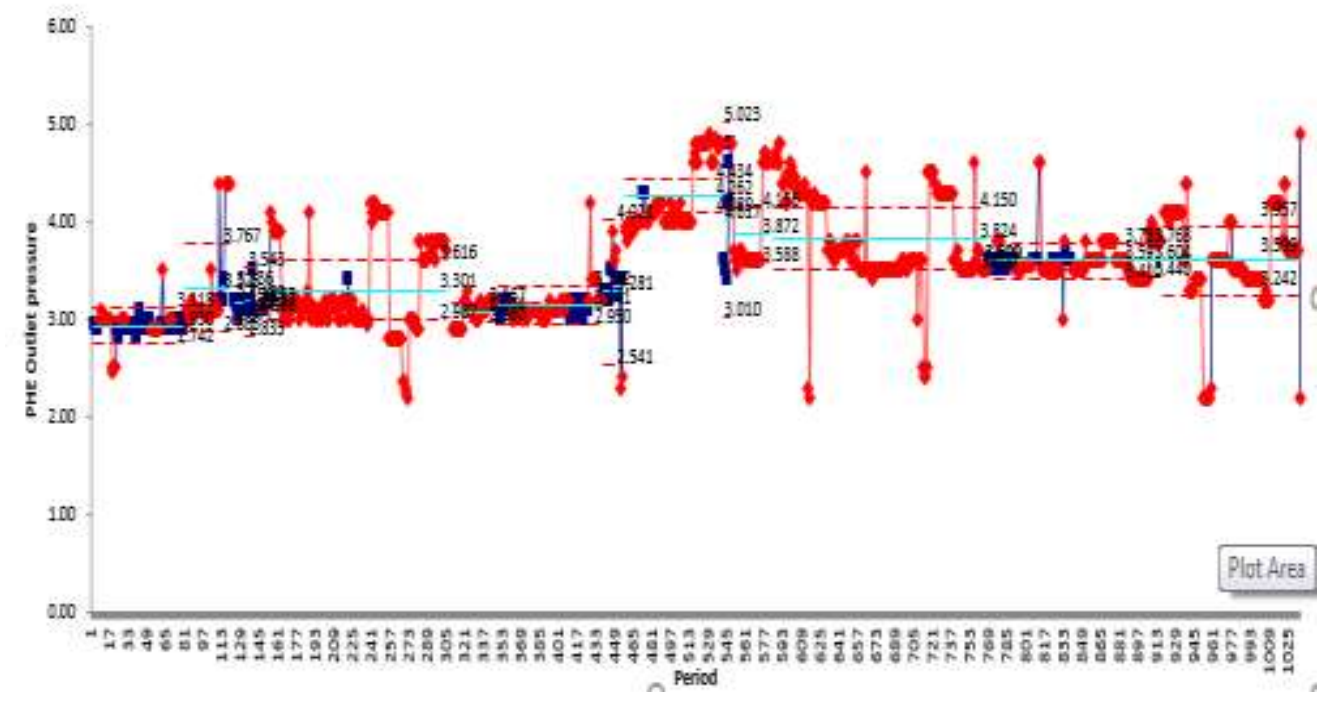

Fig (5): PHE Outlet Pressure



Fig (6): Sea Water Conductivity 


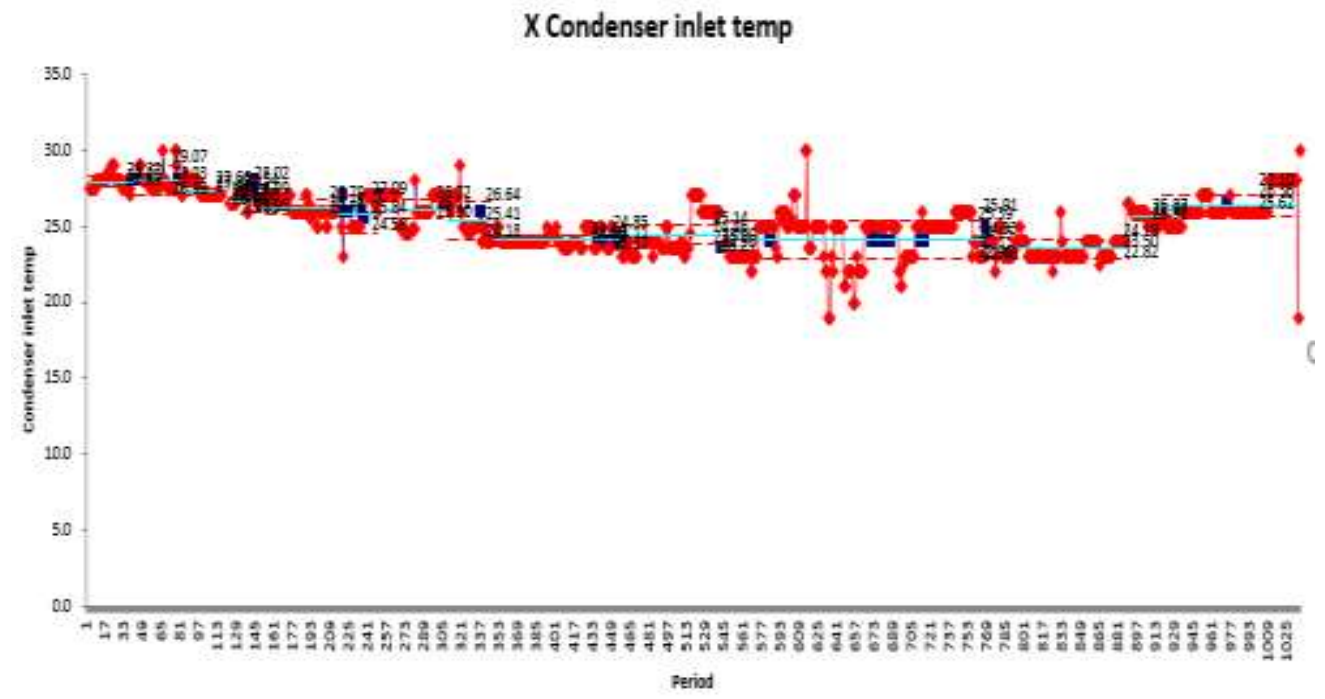

Fig (7): Condenser Inlet Temperature

The following distribution for the Pre-heater inlet temperature for the three stages, pressure, and the tank level of the Anti-foam

X SW pre-heater Me-815 inlet Temp

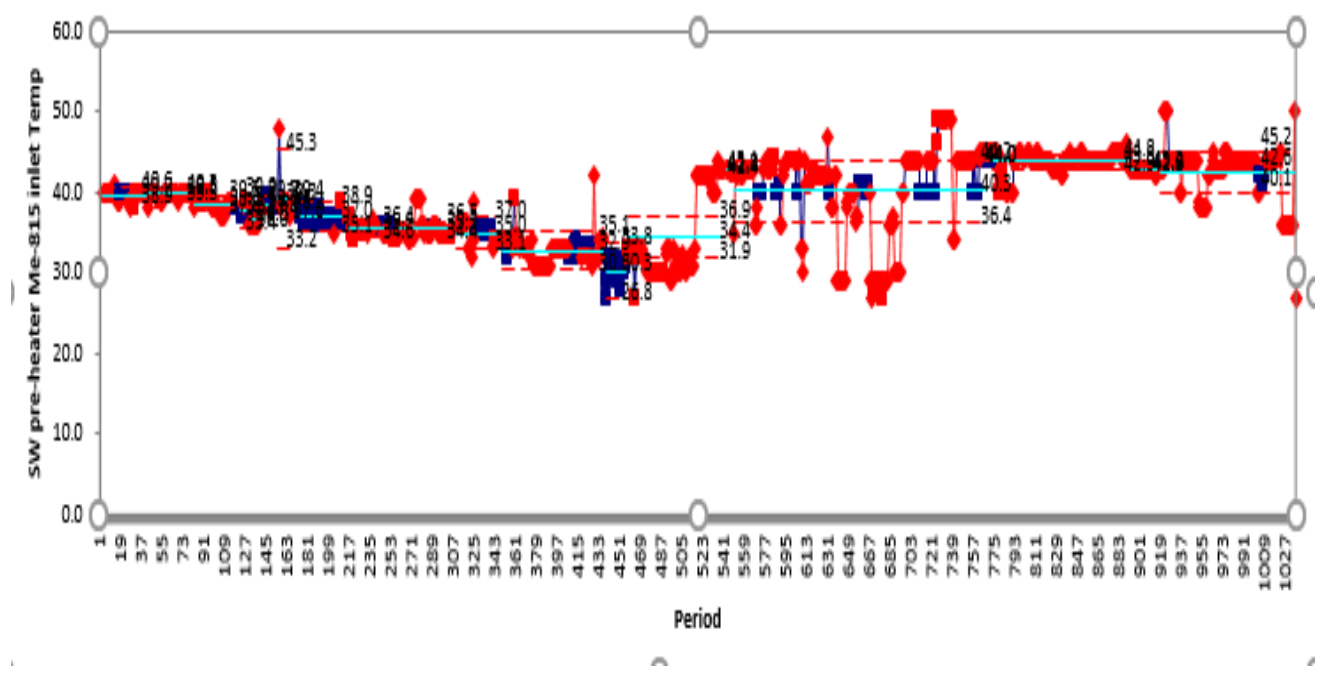

Fig (8): Sea Water Pre-heater Inlet Temperature (Stage 1) 


\section{SW pre-heater Me-816 inlet Temp}

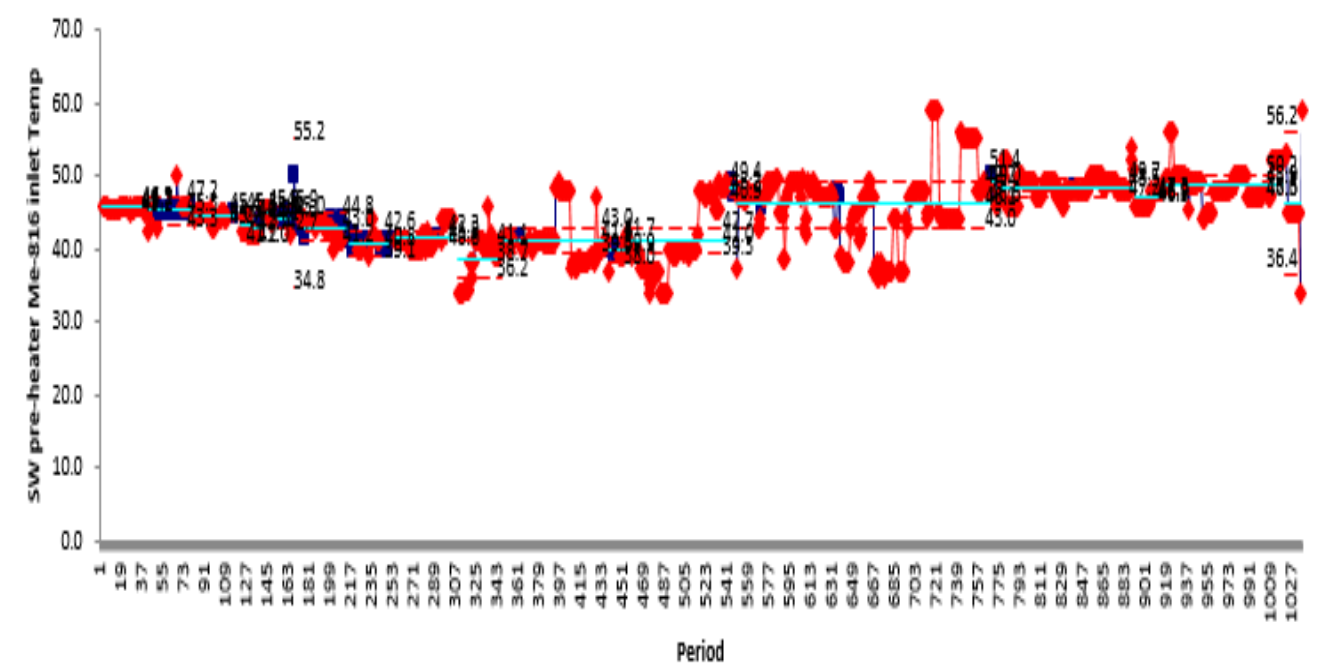

Fig (9): Sea Water Pre-heater Inlet Temperature (Stage 2)

\section{SW pre-heater Me-817 inlet Temp}

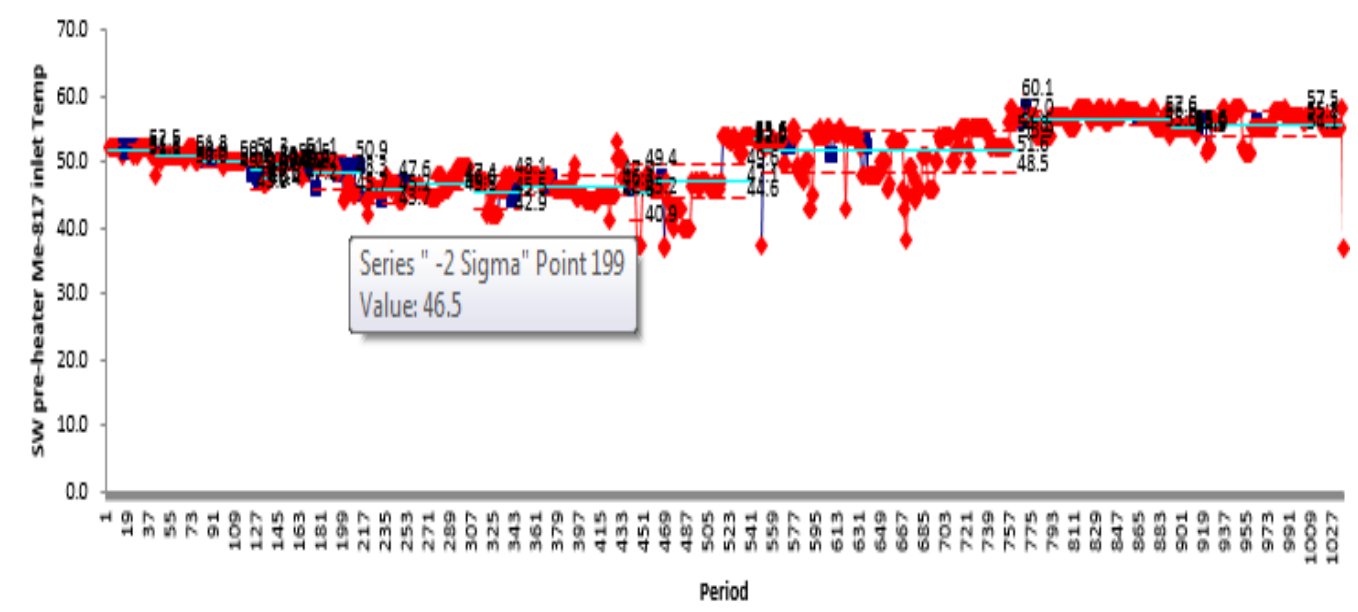

Fig (10): Sea Water Pre-heater Inlet Temperature (Stage 3) 
The following distribution for the temperature of vapor at the final stage and transfers to condenser.

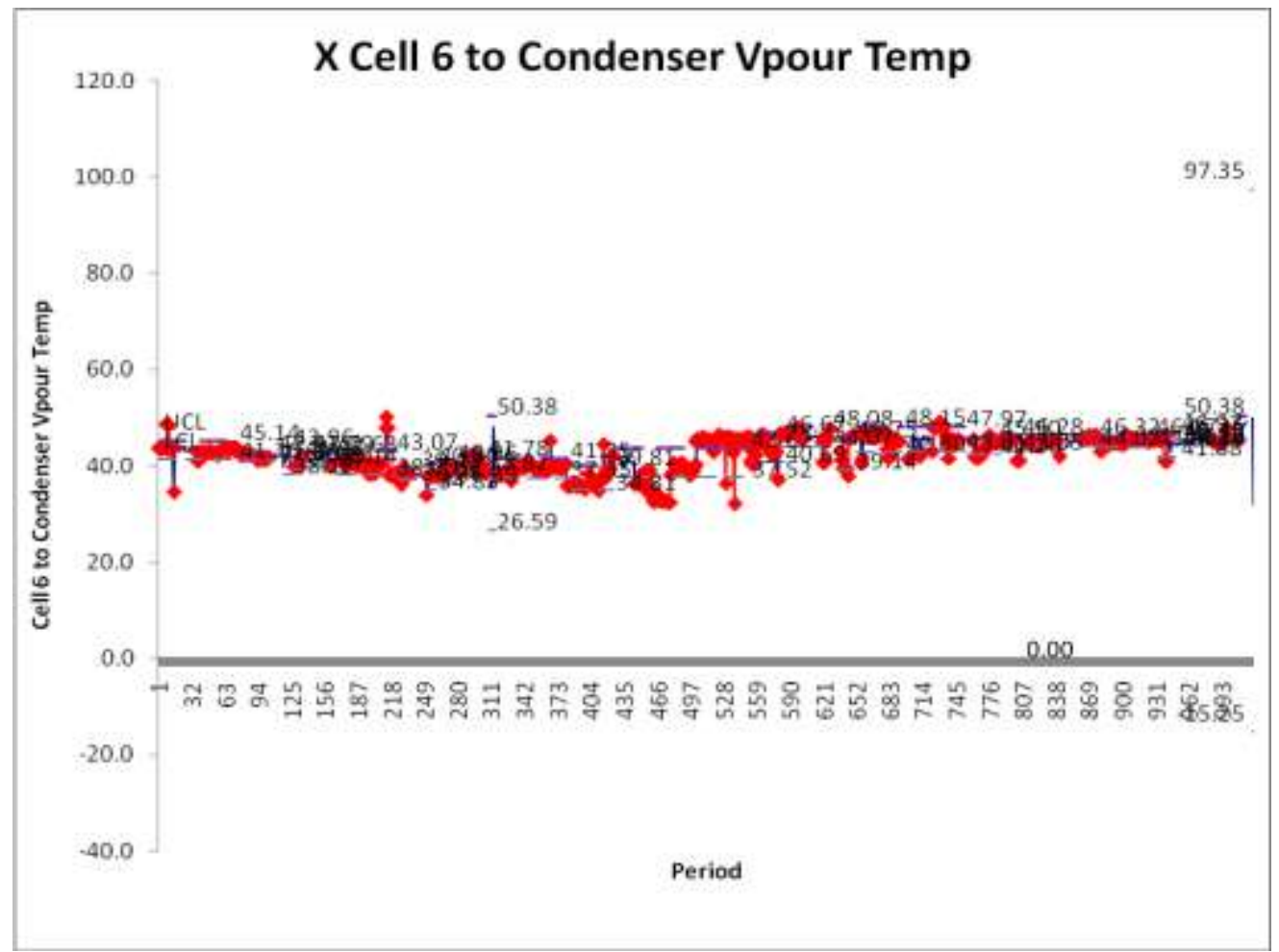

Fig (11): Cell 6 to condenser Vapor Temperature

As shown from the figures, the variations of the measurement are very high and Sea Water systems not matches with the six-sigma approach.

Developing Integrated Quality Assurance Program for the maintenance of the Sea Water Systems (Brine Plate Heat Exchangers (PHE) system, Distillate Plate Heat Exchangers (PHE) system and Condensation system): 
J. Environ. Sci.

Institute of Environmental Studies and Research - Ain Shams University

Table (1): (SIPOC) diagram for the dosing system operation

\begin{tabular}{|c|c|c|c|c|c|c|c|}
\hline 壳 & & 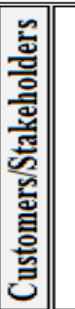 &  & 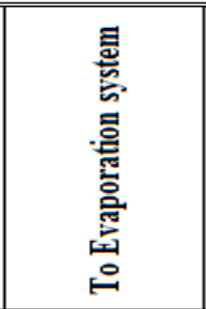 & 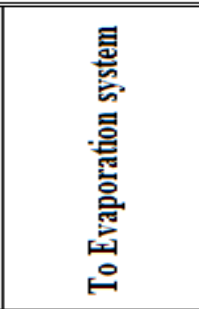 & 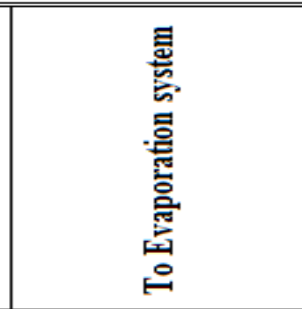 & 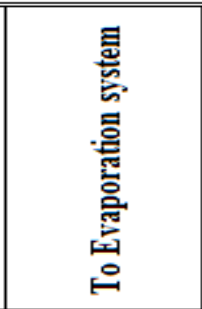 \\
\hline  & 0 & 言) &  & 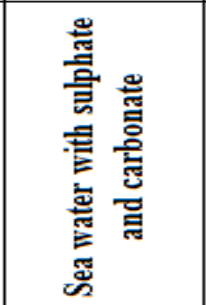 & 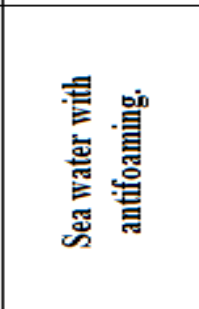 & 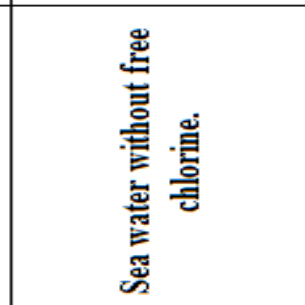 & 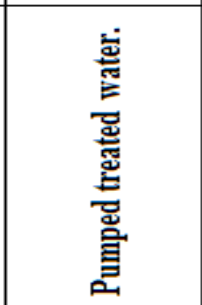 \\
\hline & a & 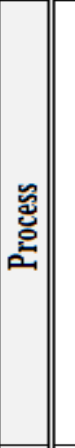 & 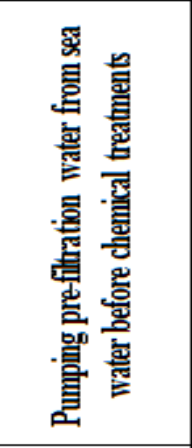 & 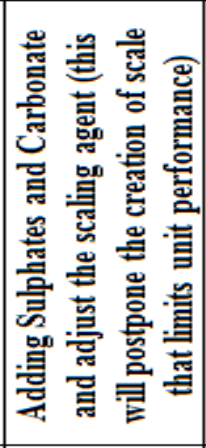 & 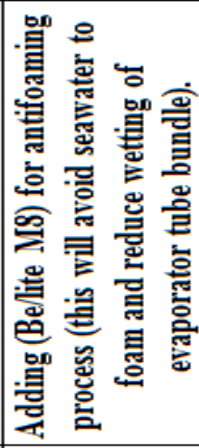 & 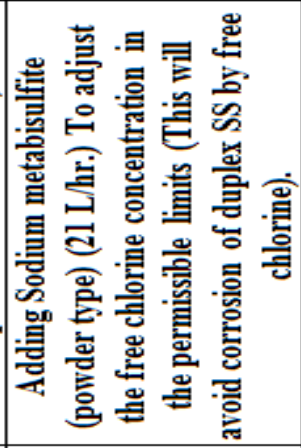 & 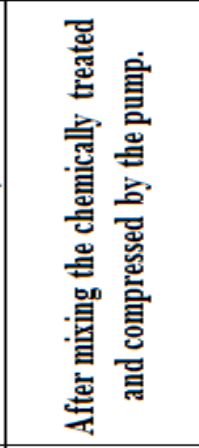 \\
\hline 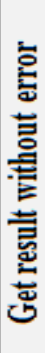 & -1 & 言 &  & 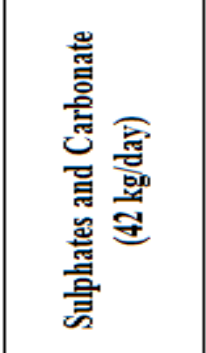 & 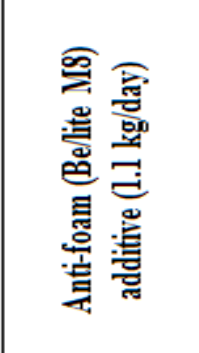 & 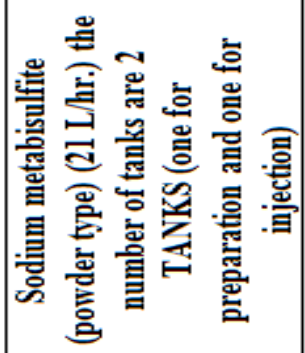 & 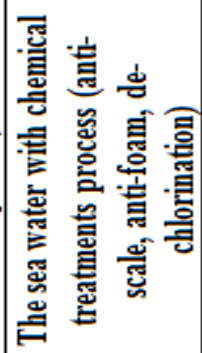 \\
\hline  & $\infty$ &  & 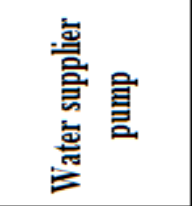 & 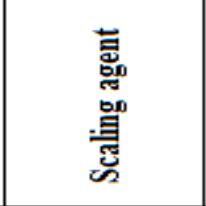 &  & 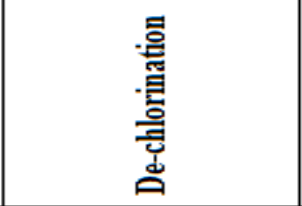 & 总总 \\
\hline
\end{tabular}






Pareto Chart

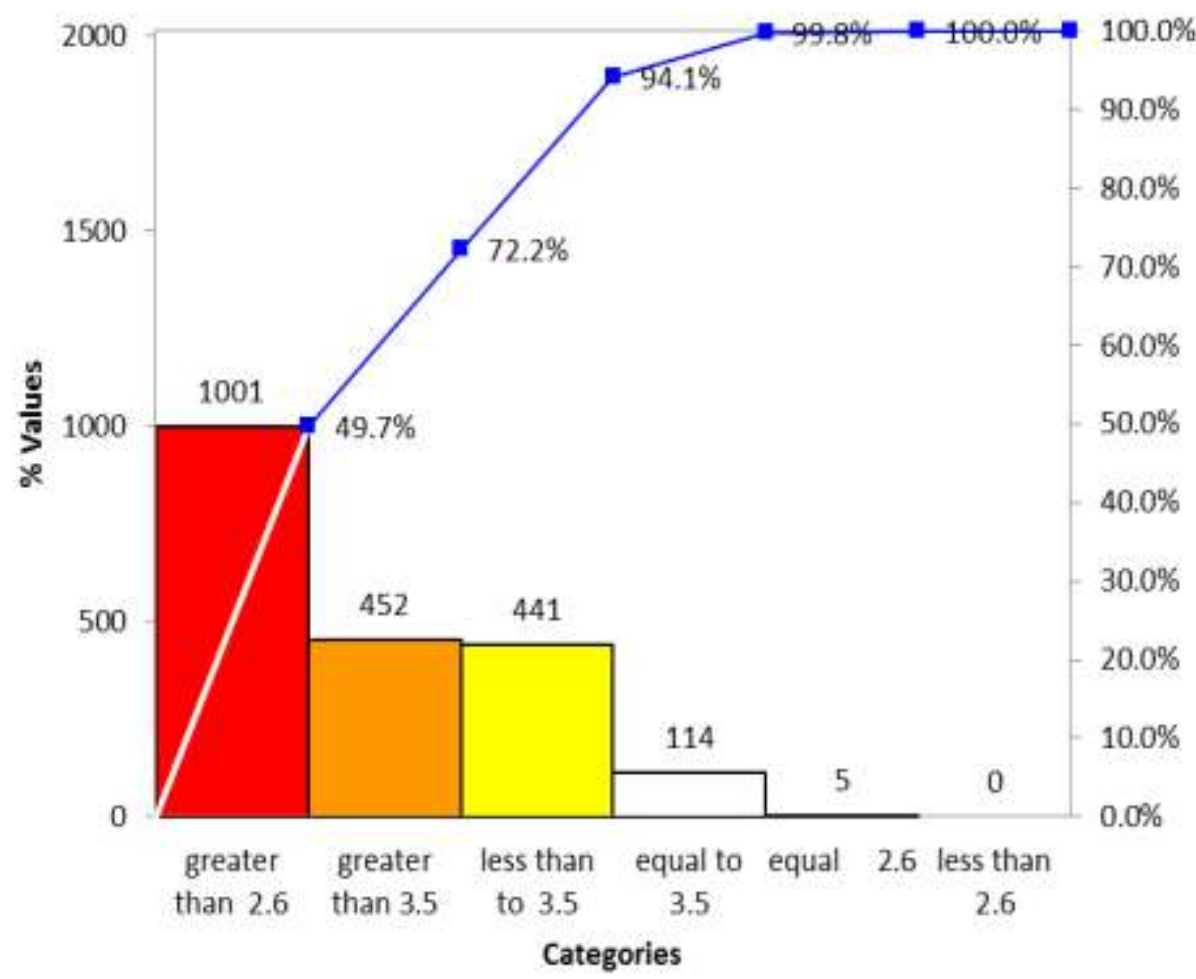

Fig (12): Pareto chart for the Brine PHE system deviations 
J. Environ. Sci.

Institute of Environmental Studies and Research - Ain Shams University

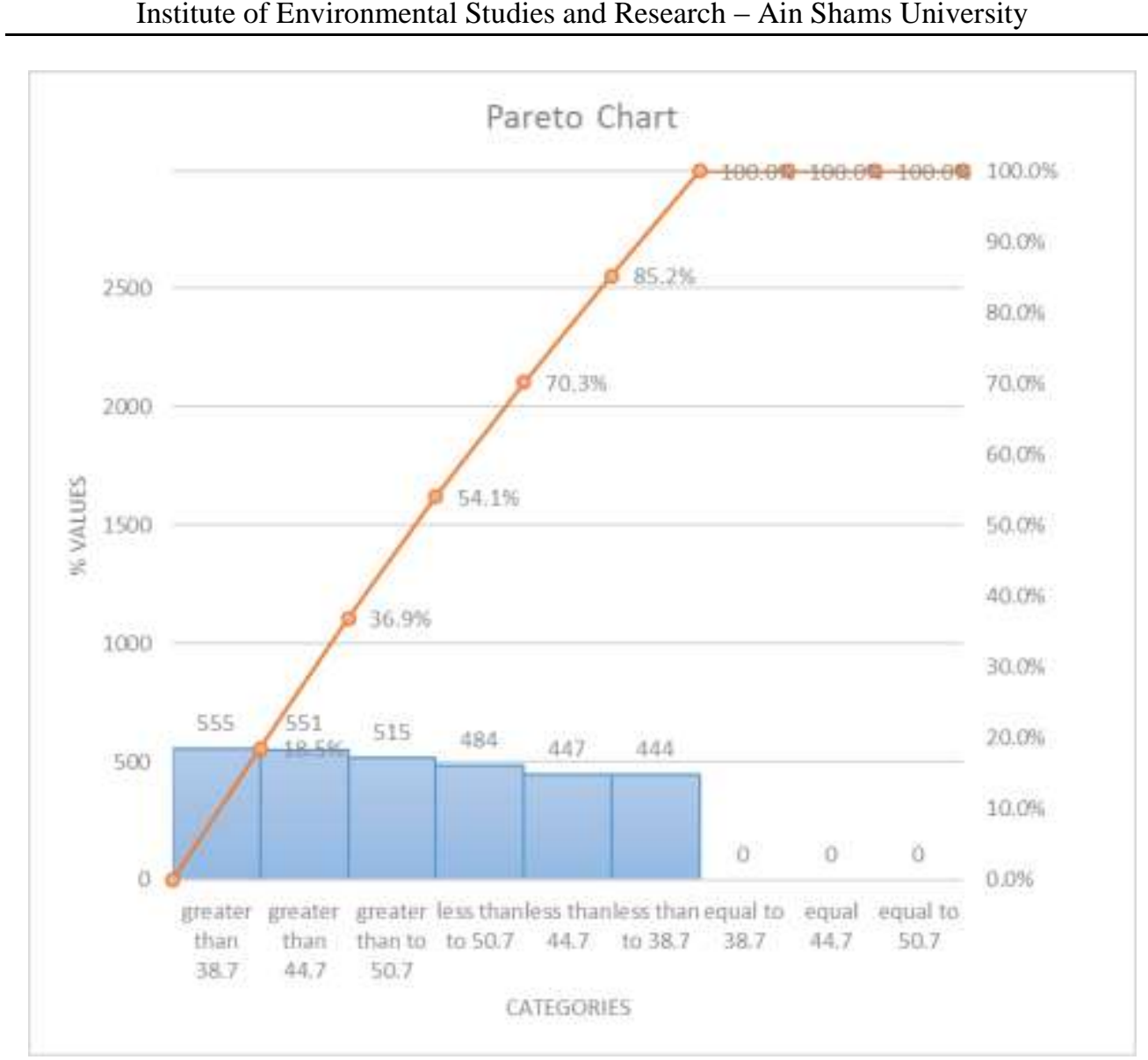

Fig.(13): Pareto chart for the Distillate PHE system deviations 




Fig.(14): Pareto chart for the Condensation PHE system deviations 


\section{Analyze phase:}

Table (2): Input controllable factors and their low and high levels

\begin{tabular}{|l|c|c|}
\hline Controllable input factor & Levels used & $\begin{array}{c}\text { High and } \\
\text { low levels }\end{array}$ \\
\hline \hline Malfunction of measuring & 10 & -1 \\
temp & 20 & +1 \\
\hline Failure of the sensing level & $60 \%$ & -1 \\
& $80 \%$ & -1 \\
\hline \multirow{2}{*}{ Operator failure } & Interpret not in time & +1 \\
\hline \multirow{2}{*}{ Maintenance failure } & Interpret on time & -1 \\
& Not on scheduled & +1 \\
\hline \multirow{2}{*}{ Calibration failure } & On scheduled & +1 \\
\hline \hline
\end{tabular}

Table (3): Experimental design strategy of the screening DOE

\begin{tabular}{|c|c|c|l|l|l|l|l|l|l|}
\hline \multicolumn{10}{|c|}{ Combination of the input factor levels } \\
\hline $\begin{array}{c}\text { No. of } \\
\text { replicates }\end{array}$ & $\begin{array}{c}\text { \# of } \\
\text { measurements }\end{array}$ & A & B & C & D & E & F & G & H \\
\hline \hline 2 & 1024 & +1 & +1 & +1 & +1 & -1 & -1 & +1 & -1 \\
\hline 2 & 1024 & -1 & +1 & +1 & -1 & -1 & -1 & +1 & -1 \\
\hline 2 & 1024 & +1 & +1 & +1 & +1 & +1 & +1 & +1 & +1 \\
\hline 2 & 1024 & -1 & -1 & -1 & -1 & +1 & +1 & -1 & +1 \\
\hline 2 & 1024 & +1 & -1 & -1 & +1 & -1 & -1 & -1 & -1 \\
\hline 2 & 1024 & -1 & -1 & -1 & -1 & -1 & -1 & -1 & -1 \\
\hline 2 & 1024 & +1 & +1 & +1 & +1 & +1 & +1 & +1 & +1 \\
\hline 2 & 1024 & -1 & +1 & +1 & -1 & +1 & +1 & +1 & +1 \\
\hline 2 & 1024 & +1 & +1 & +1 & +1 & -1 & -1 & +1 & -1 \\
\hline 2 & 1024 & -1 & -1 & -1 & -1 & -1 & -1 & -1 & -1 \\
\hline 2 & 1024 & +1 & -1 & -1 & +1 & +1 & +1 & -1 & +1 \\
\hline 2 & 1024 & -1 & -1 & -1 & -1 & +1 & +1 & -1 & +1 \\
\hline 2 & 1024 & +1 & +1 & +1 & +1 & -1 & -1 & +1 & -1 \\
\hline 2 & 1024 & -1 & +1 & +1 & -1 & -1 & -1 & +1 & -1 \\
\hline 2 & 1024 & +1 & +1 & +1 & +1 & +1 & +1 & +1 & +1 \\
\hline 2 & 1024 & -1 & -1 & -1 & -1 & +1 & +1 & -1 & +1 \\
\hline
\end{tabular}






Fig.(15): Chain of causes- and- occurrences of Sea Water failures

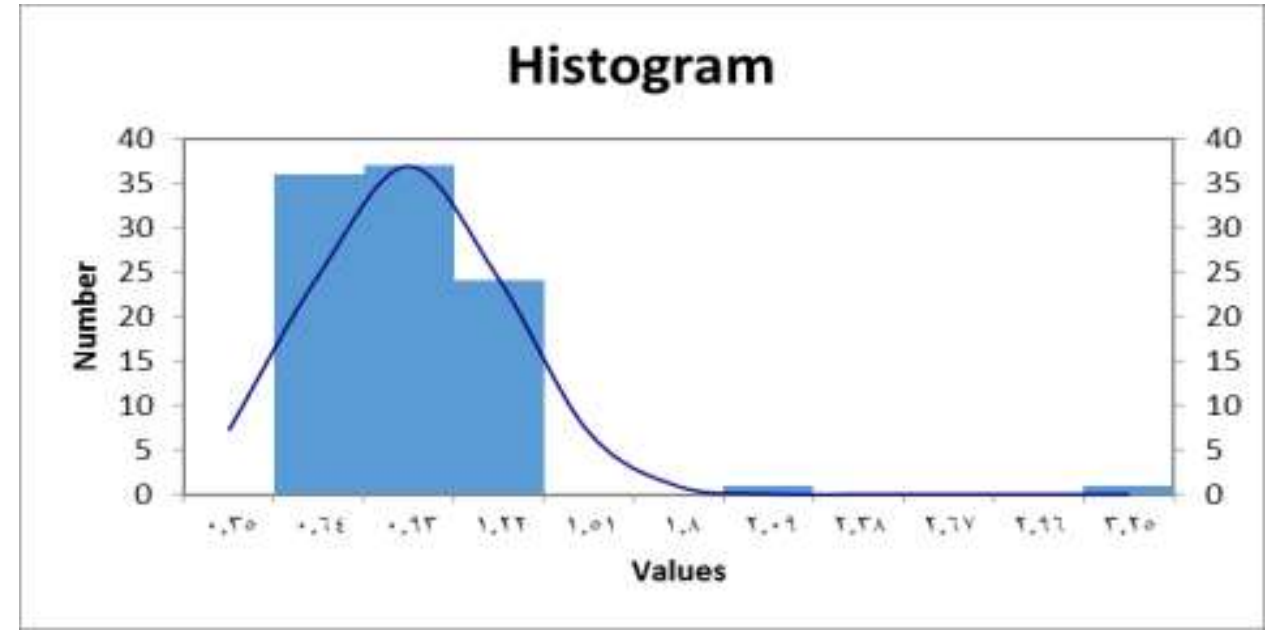

Fig.(16): Proportions follow normal distribution

Establishing Reliability Centered Maintenance Program (RCMP)

Developing the Operation and Maintenance Procedures

Calibration of the measuring devices

On - the - Job Training 
J. Environ. Sci.

Institute of Environmental Studies and Research - Ain Shams University

Table (4): The measurement results in terms of proportion of deviations for the four CTQs

\begin{tabular}{|c|c|c|c|c|c|c|c|c|c|c|c|c|c|}
\hline \multirow[b]{2}{*}{ 苞 } & \multirow[b]{2}{*}{ 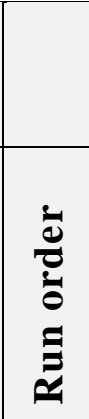 } & \multicolumn{8}{|c|}{$\begin{array}{c}\text { Combination of the input } \\
\text { factor levels }\end{array}$} & & \multicolumn{3}{|c|}{$\begin{array}{c}\text { Proportions of } \\
\text { defectives for each } \\
\text { CTQ } \\
\end{array}$} \\
\hline & & A & B & C & D & $\mathbf{E}$ & $\mathbf{F}$ & $\mathbf{G}$ & $\mathbf{H}$ & 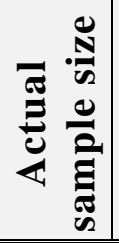 & 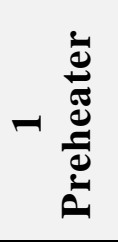 & N &  \\
\hline 1 & 10 & +1 & +1 & +1 & +1 & +1 & -1 & +1 & -1 & 100 & 1 & 0.98 & 1 \\
\hline 2 & 11 & -1 & +1 & +1 & -1 & -1 & -1 & +1 & -1 & 200 & 1 & 1 & 1 \\
\hline 1 & 24 & +1 & +1 & +1 & +1 & +1 & +1 & +1 & +1 & 100 & 1 & 1 & 0.98 \\
\hline 2 & 50 & -1 & -1 & -1 & -1 & -1 & +1 & -1 & +1 & 120 & 1 & 0.98 & 0.53 \\
\hline 1 & 30 & +1 & -1 & -1 & +1 & +1 & -1 & -1 & -1 & 120 & 1 & 0.98 & 1 \\
\hline 2 & 40 & -1 & -1 & -1 & -1 & -1 & -1 & -1 & -1 & 120 & 1 & 0.98 & 1 \\
\hline 1 & 33 & +1 & +1 & +1 & +1 & +1 & +1 & +1 & +1 & 130 & 1 & 0.98 & 0.86 \\
\hline 2 & 22 & -1 & +1 & +1 & -1 & -1 & +1 & +1 & +1 & 110 & 1 & 0.98 & 0.85 \\
\hline 1 & 11 & +1 & +1 & +1 & +1 & +1 & -1 & +1 & -1 & 120 & 1 & 0.98 & 1 \\
\hline 2 & 15 & -1 & -1 & +1 & -1 & -1 & -1 & -1 & -1 & 100 & 1 & 0.98 & 0.82 \\
\hline 1 & 10 & +1 & -1 & +1 & +1 & +1 & +1 & -1 & +1 & 100 & 1 & 0.98 & 0.53 \\
\hline 2 & 35 & -1 & -1 & -1 & -1 & -1 & +1 & -1 & +1 & 110 & 1 & 0.98 & 0.59 \\
\hline 1 & 37 & +1 & +1 & -1 & +1 & +1 & -1 & +1 & -1 & 120 & 1 & 0.98 & 0.45 \\
\hline 2 & 39 & -1 & +1 & -1 & -1 & -1 & -1 & +1 & -1 & 120 & 1 & 0.98 & 0.74 \\
\hline 1 & 44 & +1 & +1 & +1 & +1 & +1 & +1 & +1 & +1 & 130 & 1 & 0.98 & 0.90 \\
\hline 2 & 80 & -1 & -1 & +1 & -1 & -1 & +1 & -1 & +1 & 110 & 1 & 0.98 & 1 \\
\hline 1 & 26 & +1 & +1 & +1 & +1 & +1 & -1 & +1 & -1 & 120 & 1 & 0.98 & 001 \\
\hline
\end{tabular}


Table (4): The measurement results in terms of proportion of deviations for the four CTQs

\begin{tabular}{|c|c|c|c|c|c|c|c|c|c|c|c|c|c|}
\hline \multirow[b]{2}{*}{ 递 } & \multirow[b]{2}{*}{ 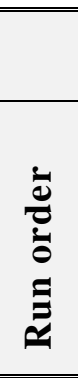 } & \multicolumn{8}{|c|}{$\begin{array}{l}\text { Combination of the input } \\
\text { factor levels }\end{array}$} & \multirow[b]{2}{*}{  } & \multicolumn{3}{|c|}{$\begin{array}{c}\begin{array}{c}\text { Proportions of defectives } \\
\text { for each CTQ }\end{array} \\
\end{array}$} \\
\hline & & A & B & C & D & $\mathbf{E}$ & $\mathbf{F}$ & $\mathbf{G}$ & $\mathbf{H}$ & & 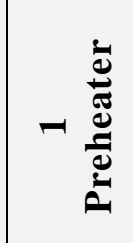 & N & 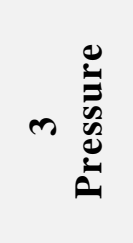 \\
\hline 2 & 20 & $\mid-1$ & +1 & -1 & -1 & -1 & -1 & +1 & -1 & 120 & 1 & 0.98 & 0.90 \\
\hline 1 & 90 & +1 & +1 & -1 & +1 & +1 & +1 & +1 & -1 & 134 & 1 & 0.98 & 0.77 \\
\hline 2 & 16 & -1 & +1 & -1 & -1 & -1 & +1 & +1 & +1 & 120 & 1 & 0.98 & 1 \\
\hline 1 & 22 & +1 & +1 & +1 & +1 & +1 & -1 & -1 & +1 & 300 & 1 & 0.98 & 1 \\
\hline 2 & 50 & -1 & +1 & +1 & -1 & -1 & -1 & -1 & -1 & 300 & 1 & 0.98 & 0.78 \\
\hline 1 & 55 & +1 & -1 & +1 & +1 & +1 & +1 & -1 & -1 & 500 & 1 & 0.98 & 0.96 \\
\hline 2 & 66 & -1 & -1 & -1 & -1 & -1 & +1 & +1 & +1 & 600 & 1 & 0.98 & 0.86 \\
\hline 1 & 30 & +1 & -1 & +1 & +1 & +1 & -1 & +1 & +1 & 500 & 1 & 0.98 & 0.86 \\
\hline 2 & 10 & -1 & +1 & +1 & -1 & -1 & -1 & +1 & -1 & 800 & 1 & 0.98 & 0.91 \\
\hline 1 & 20 & +1 & +1 & +1 & +1 & +1 & +1 & -1 & -1 & 600 & 1 & 0.98 & 0.88 \\
\hline 2 & 23 & -1 & +1 & -1 & -1 & -1 & +1 & -1 & +1 & 700 & 1 & 0.98 & 0.86 \\
\hline 1 & 25 & +1 & -1 & -1 & +1 & +1 & -1 & -1 & +1 & 100 & 1 & 0.98 & 0.52 \\
\hline 2 & 28 & -1 & -1 & -1 & -1 & -1 & -1 & +1 & -1 & 150 & 1 & 0.98 & 0.88 \\
\hline 1 & 29 & +1 & -1 & +1 & +1 & +1 & +1 & +1 & -1 & 800 & 1 & 0.98 & 0.89 \\
\hline 2 & 23 & -1 & +1 & +1 & -1 & -1 & +1 & +1 & +1 & 700 & 1 & 0.98 & 0.85 \\
\hline
\end{tabular}


J. Environ. Sci.

Institute of Environmental Studies and Research - Ain Shams University

Table (5): ANOVA of the screening DOE and determination of the significant factors

\begin{tabular}{|c|c|c|c|c|c|c|c|c|c|c|c|c|c|c|}
\hline Hora Single Factor & 2 & 005 & & & & & & & & & & & & \\
\hline & & & & & & ISO & 0.48872 & & & & & & & \\
\hline SUIIIARY & & & & & & HSD & 0.74498 & & & & & & & \\
\hline Goups & Count & Sum & Averge & Variance & & Schefe 1 & 1.854874 & & & & & & & \\
\hline$A$ & 32 & 0 & 0 & 1.03228 & & Post Hox A & A $\quad B$ & 8 & C & D & $E$ & $F$ & G & H \\
\hline B & 32 & 6 & 0.1875 & 0.995868 & & $B$ & 0.1875 & & & & & & & \\
\hline C & 32 & 6 & 0.1875 & 0.995868 & & C & 0.1875 & 0 & & & & & & \\
\hline D & 32 & 0 & 0 & 1.03258 & & D & $0^{-}$ & 0.1875 & $0.185^{-}$ & & & & & \\
\hline E & 32 & 0 & 0 & 1.032258 & & E & 0 & 0.1875 & 0.185 & 0 & & & & \\
\hline$F$ & 32 & 0 & 0 & 1.032258 & & $F$ & 0 & 0.1875 & 0.185 & 0 & 0 & & & \\
\hline G & 32 & 6 & 0.1875 & 0.995868 & & G & 0.1875 & 0 & 0 & 0.1875 & 0.1875 & 0.1875 & & \\
\hline H & 32 & -2 & 2.00625 & 1.026226 & & H & 00025 & 025 & 025 & 0.625 & 0,0625 & 0.0625 & 02 & \\
\hline Pressure & 32 & 31.4 & 0.98125 & $2.4 \mathrm{E}-15$ & & Pressue & 099025 & 0.79375 & 0.79375 & 098125 & 0.98125 & 0.96125 & 0.78975 & 1.04375 \\
\hline & & & & & & \multicolumn{5}{|c|}{ Colord cels hrve signficant mean dferences } & & & & \\
\hline & & & & & & & & & & & & & & \\
\hline AIONA & \multicolumn{8}{|c|}{ ReactlluI Hyouhess beca.se $p<0.15$ Oleans are Different:) } & & & & & & \\
\hline Source of Variation & SS & of & US & $F$ & P-Value & Fot & & & & & & & & \\
\hline Betveen Grucs & 2651 & 8 & 3.31375 & 3661519 & 000 & 1.97608 & & & & & & & & \\
\hline Wrin Grous & 2525018 & 279 & 0965021 & & & & & & & & & & & \\
\hline & & & & & & & & & & & & & & \\
\hline Total & 279.0108 & 287 & & & & & & & & & & & & \\
\hline
\end{tabular}

Significant factors: the "maintenance failure" is significant; the "device calibration" is important.

\begin{tabular}{|c|c|c|c|c|c|c|c|c|c|c|c|c|c|}
\hline Anva Single Factor & a & 005 & & & & & & & & & & & \\
\hline & & & & & LSD & 0.48821 & & & & & & & \\
\hline SUIIIARY & & & & & HSD & 074509 & & & & & & & \\
\hline Gous & Count & Sum & Averae Variane & & Scheff & 1.862249 & & & & & & & \\
\hline $\bar{A}$ & 32 & 0 & 01.032258 & & Post Hoc & A & 8 & C & 0 & E & $F$ & 6 & $H$ \\
\hline$B$ & 32 & 6 & 0.18750 .995908 & & $B$ & 01875 & & & & & & & \\
\hline C & 32 & 6 & 0.18750 .995980 & & C & 01875 & 0 & & & & & & \\
\hline 0 & 32 & 0 & 01.03225 & & 0 & 0 & 01875 & 0.1875 & & & & & \\
\hline$E$ & 32 & 0 & 01.03225 & & E & 0 & 01875 & 0.1875 & 0 &  & & & \\
\hline F & 32 & 0 & 01.03225 & & F & 0 & 01875 & 0.1875 & 0 & 0 & 0 & & \\
\hline G & 32 & 6 & 0.18750 .995968 & & G & 01875 & 0 & 0 & 0.1875 & 0.1875 & $5 \quad 0.1875$ & & \\
\hline H & 32 & -2 & A. 06251.02022 & & $H$ & 0025 & 025 & 025 & 0.0225 & 0.0625 & 5.0062 & 0.25 & \\
\hline temo & 32 & 27.17 & 0.8496630 .026112 & & Enp & 0.849163 & 0.661503 & 0.661503 & 0849663 & 0.849063 & 3. 0849063 & 3.6601563 & 0.911500 \\
\hline & & & & & \multicolumn{5}{|c|}{ Colored cels hare sioficart mean diferences } & & & & \\
\hline & & & & & & & & & & & & & \\
\hline ANOH & & \multicolumn{6}{|c|}{ Reectlliul Hvoohess becsise o < 0.05 (leans are D fifret) } & & & & & & \\
\hline Source of Varition & $S S$ & df & MS & P./ale & Fodt & & & & & & & & \\
\hline Betveen Grups & 2008803 & & 2512532767045 & 0006 & 1.971606 & & & & & & & & \\
\hline Whin Gours & 253.3095 & 279 & 0.907919 & & & & & & & & & & \\
\hline & & & & & & & & & & & & & \\
\hline Iotal & 273.4775 & 287 & & & & & & & & & & & \\
\hline
\end{tabular}

Significant factors: the "maintenance failure" is significant; the "device calibration" is important and the combination between calibration and maintenance. 
Donia, Noha, et al.

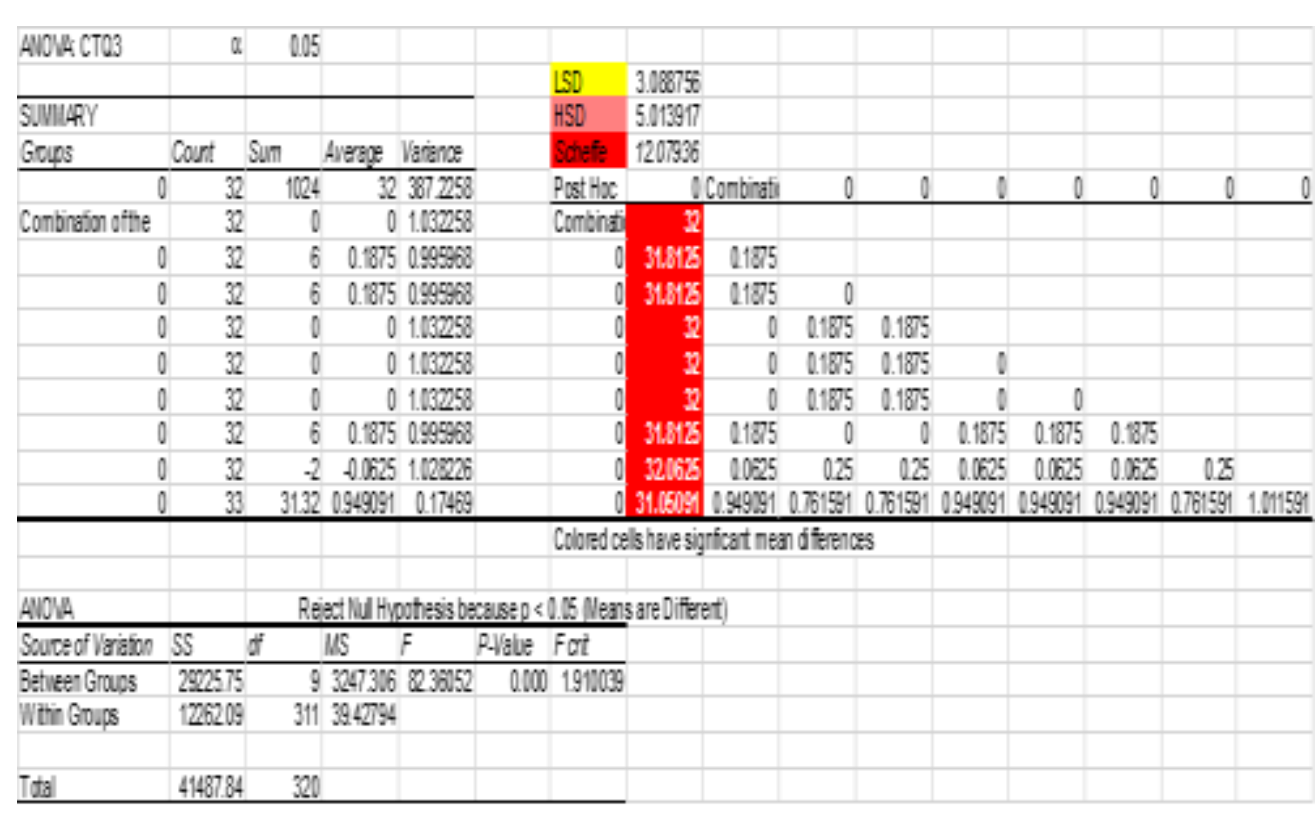

Significant factors: the "sensing level" is significant; the "maintenance failure" is important, and the combination between calibration and level sensing, and the combination between maintenance failure and the sensing level. 
J. Environ. Sci.

Institute of Environmental Studies and Research - Ain Shams University

\section{ANOVA Regression}

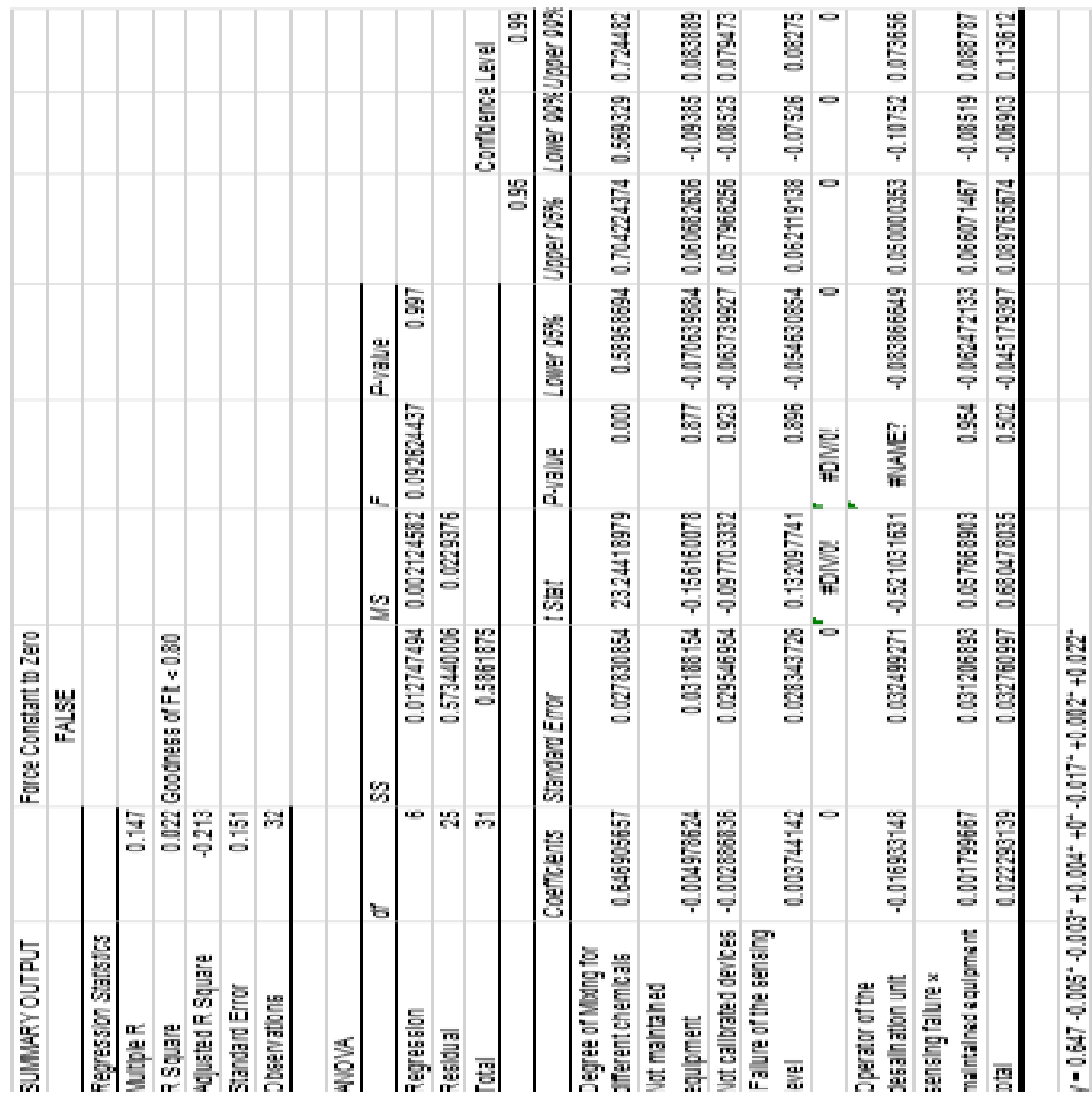


Table (6): metrics measured based on monitored data

\begin{tabular}{|c|c|c|c|c|c|c|}
\hline  & 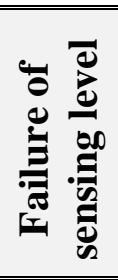 & 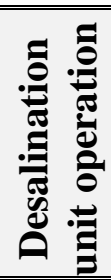 & そ。 & Z产冚 & 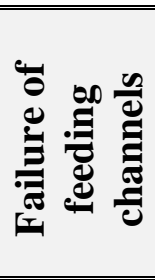 & 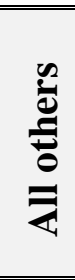 \\
\hline 55 & 59 & 18 & 530 & 405 & 33 & 102 \\
\hline & Num & $\begin{array}{l}\text { Number } \\
\text { of opp } \\
\text { ate of } \\
\text { Sigma }\end{array}$ & $\begin{array}{l}\text { measures } \\
\text { of variati } \\
\text { tunities pe } \\
\text { fectives = } \\
\operatorname{vel}(\mathrm{Z})=\end{array}$ & $\begin{array}{l}=1024 \\
\text { ns }=597 \\
\text { r defects= } \\
59 \% \\
.73\end{array}$ & & \\
\hline
\end{tabular}

Improve \& control phase:-

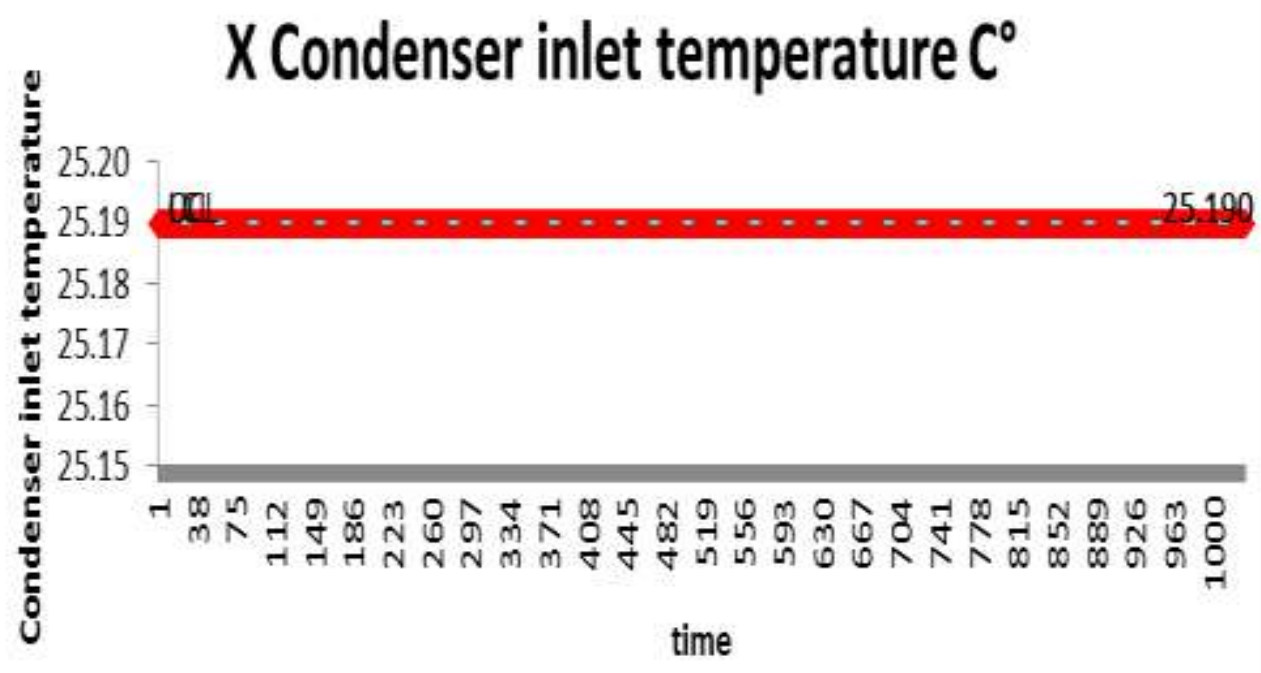

Fig. (18): Condenser inlet temperature after adjustment 


\section{Flowrate $\mathrm{m}^{\wedge} \mathbf{3} / \mathrm{hr}$}

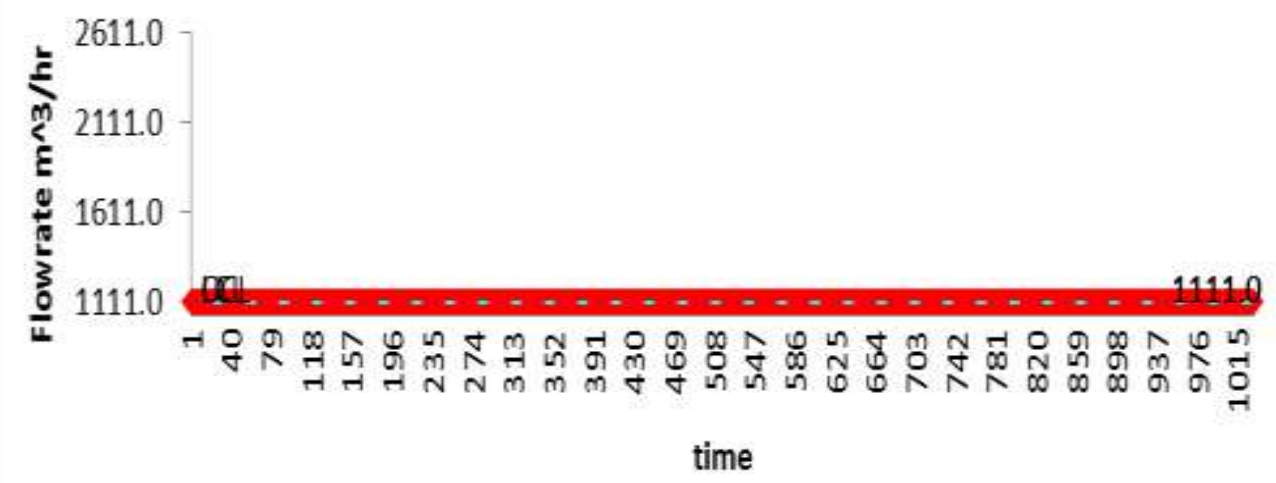

Fig. (19): Water Flowrate after adjustment



Fig. (20): PHE outlet pressure after adjustment 
From the previous figures all the outputs of the critical components in the system adjusted and under control.

Area of action 2 - calibration of the measuring devices.

The sensors that used for starting the actuation system shall have calibration procedures to fulfill the requirements needed for the continuous operation of the Sea Water System without any interruption.

Area of action 3 - On-the-Job Training.

An on-the-job training program was implemented on the Sea Water System as a part of the MED/TCD plant in order to increase the knowledge and the technical skills of the personnel. The on-the-job training program covers several topics, including the following ones:

- promotion and dissemination of the best practices to be adopted in the operational procedures involved in maintenance activities and in applying the quality assurance procedures;

- standardization of the inspection criteria in all the control points of the process, in order to ensure exactly the same criteria are adopted by everyone; and

- provision of knowledge, rehabilitation, education, and training of personnel. And establishing guidelines to increase the ability of people to distinguish items or parts need a maintenance in different types faults.

\section{Six- sigma calculation:}

1- Standard Deviation Calculation

$$
\sigma=\sqrt{\frac{\sum(x-\mu)}{N}}
$$


2- Normal distribution and process capability

$$
f(x)=\frac{1}{\sigma \sqrt{2 \pi}} e^{-\frac{(x-\mu)^{2}}{\sigma \sqrt{2 \pi}}}
$$

3- Arithmetic mean of grouped data

$$
\mu=\frac{\sum f X}{N}
$$

Where $\mu$ is the arithmetic mean, $\mathrm{X}$ is the midpoint, $\mathrm{f}$ is the frequency in each interval, and $\mathrm{N}$ is the total number of the frequencies.

4- Range $=$ highest value - lowest value

5- Variance

$$
\sigma^{2}=\sum \frac{\left(x_{i}-\mu\right)^{2}}{N}
$$

6- Poisson distribution, rolled throughput yield, and DPMO

$$
P(x)=\frac{\mu^{x} e^{-\mu}}{x !}
$$

Where $\mathrm{P}(\mathrm{x})$ is the probability for a unit to contain $\mathrm{x}$ defects, and $\mu$ is the mean defect per unit. This equation can be rewritten if the DPU is known,

$$
P(x)=\frac{D P U^{x} e^{-D P U}}{x !}
$$

7- Estimating the Population Mean with Large Sample Sizes

Using the Central Limit Theorem, we have determined that the $\mathrm{Z}$ value for sample means can be used for large samples.

$$
z=\frac{\bar{X}-\mu}{\sigma / \sqrt{N}}
$$

By rearranging this formula, we can derive the value of $\mu$, 


$$
\mu=\bar{X} \pm{ }^{z \sigma} / \sqrt{N}
$$

Where,

$X+(z \sigma) / \sqrt{N}$ is the upper confidence limit (UCL) and

$X-(z \sigma) / \sqrt{N}$ is the lower confidence limit (LCL).

8- Statistical Process Control: The first step when creating a p-chart is to calculate the proportion of nonconformity for each sample.

9- The p-chart

$$
p=\frac{m}{b}
$$

Where $\mathrm{m}$ represents the number of nonconforming items, $\mathrm{b}$ is the number of items in the sample, and $\mathrm{p}$ is the proportion of nonconformity.

$$
\bar{p}=\frac{p_{1}+p_{2}+p_{3}+\cdots+p_{k}}{k}
$$

Where, $\bar{p}$ is the mean proportion, $\mathrm{k}$ is the number of samples audited, and $p_{k}$ is the kth proportion obtained. The control limits of a p-chart are:

$L C L=\bar{p}-3 \sqrt{\frac{\bar{p}(1-\bar{p})}{n}}$
$C L=\bar{p}$
$U C L=\bar{p}+3 \sqrt{\frac{\bar{p}(1-\bar{p})}{n}}$

and $\bar{p}$ represents the center line.

10- Process Capability Analysis

- Short-term potential capabilities $\mathrm{C}_{\mathrm{p}}$ and $\mathrm{C}_{\mathrm{r}}$.

$$
C_{p}=\frac{U S L-L S L}{U C L-L C L}=\frac{U S L-L S L}{6 \sigma}
$$


Where USL, LSL are upper specific limits and lower specific limits respectively.

- Capability ratios, $C_{r}$

$C r=\frac{1}{C_{p}}=\frac{6 \sigma}{U S L-L S L}$

11- Analysis of Variance (ANOVA)

$$
S S E=\sum_{i=1}^{n j} \sum_{j=1}^{k}\left(X_{i j}-\bar{X}_{j}\right)^{\wedge} 2
$$

12- Regression Analysis

- The regression equation: The independent variable is known with certainty and only that variable can affect the response variable ${ }^{\wedge} \mathrm{y}$, the model that will be built will generate an exact predictable output.

$\hat{y}=f(x)$

$\hat{y}=\beta_{1} x+\beta_{0}$

Where,

$\beta_{0}$ representing the $y$-intercept and,

$\beta_{1}$ being the slope of the line.

\section{CONCLUSION}

The six-sigma method based on the DMAIC roadmap is a helpful method to understand the problem through the define phase of the Sea Water System and determine that most of the variations of the outputs of the system comes from the lack of maintenance of the system and the calibration of devices not maintained. Further data and measures were collected in the measure phase by means of operation output measures, which led to the estimation of the 
performance baseline of the operation process. In the analyze phase of DMAIC approach, a set of studies, including DOE, were conducted to identify the root causes of variation of the measures. Some of the relevant causes had origin in calibration of the devices itself, but others had origin in downstream operations where maintenance of equipment no obtained. The improve phase involved the development and implementation of a set of improvement actions that were grouped around four areas of action. Each action shall apply in the philosophy of integration management system, not each action applies alone. The results after applying the four actions show that the behavior of the chemical dosing system enhanced and followed the six-sigma principle. The effectiveness of the improvement actions was also confirmed by the significant enhancement on the values of the operation parameters.

\section{REFERENCES}

Black, K. \& Revere, L. (2006): "Six Sigma arises from the ashes of TQM with a twist", InternationalJournal of Health Care Quality Assurance, Vol. 19 No. 3, pp. 259-266.

El-Haik, B. S. \& Al-Aomar, R. (2006): Simulation-Based Lean Six Sigma and Design for Six Sigma, Wiley, Hoboken, NJ.

Goldstein, M. (2001): "Six Sigma program success factors", Six Sigma Forum Magazine, Vol. 1 No. 1, pp. 36-45.

Senapati, N. R. (2004): "Six Sigma: myths and realities", International Journal of Quality and Reliability Management, Vol. 21 No. 6, pp. 683-690.

Coronado, R. B. \& Antony, J. (2002): Critical Success Factors for the Successful Implementation of Six Sigma Projects in Organizations. The TQM Magazine, 14, 92-99. 
Robert, G. Launsby, Mark J. Kiemele Stephen R. Schmidt: Understanding Industrial Designed Experiments (1994).

Issa Bass Barbara Lawton, Ph.D., Lean Six Sigma Using SigmaXL \& Minitab, The McGraw-Hill Companies.

David, M. Levine. (2006): "Statistics for Six Sigma Green Belts with Minitab® And JMPTM"

NJ: Prentice Hall (2001): Engineers and Scientists UsingMicrosoft Excel and Minitab.

Kai, Yang (2005): Design for Six Sigma for Service.

Forrest, W. Breyfogle (1999): Implementing Six Sigma,Smarter Solutions UsingStatistical Methods.

D. H. Stamatis (2003): Six Sigma And BeyondTheImplementationProcess.

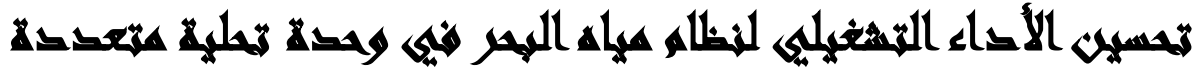

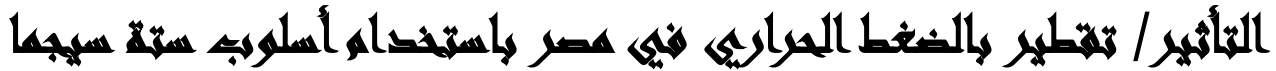

[०]

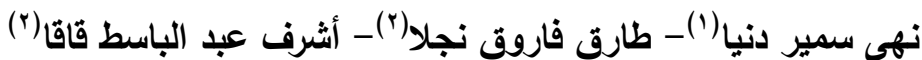

$$
\begin{aligned}
& \text { () معهد الدراسات والبحوث البيئية، جامعة عين شمس بارف) هيئة المحطات النووية لنوليد الكهرباء } \\
& \text { المسترلتص }
\end{aligned}
$$

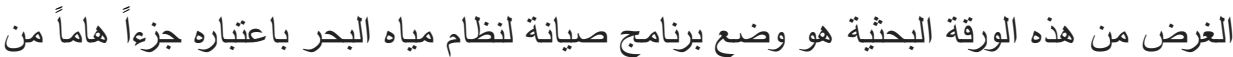


تحلية المياه باعتبار هذا النظام هو المورد الرئيسي للمياه لباقي أجزاء المحطة، وكذللك تحسين أداء وحدة تحلية المياه، وزيادة عمر أجزاء المحطة. المنهجية/النهج: من خلاهل تطبيق المنهج العلمي (أسلوب أربع خطوات) بالإضافة إلى دورة (خطط-



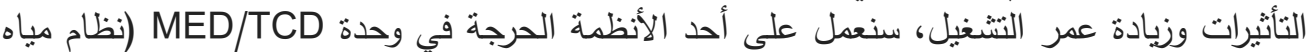
البحر (SWS)، حيث يتم إنشاء برنامج صبانة باستخدام فلسفة ستة سيجما، باستخدام منهجية (حدد- 
قيس- حلا- حسن- تحكم (DMAIC)) لحل الششاكل في وحدة MED/TCD، لزيادة موثوقية

واناحية وزيادة عمر الوحدة (MED/TCD)

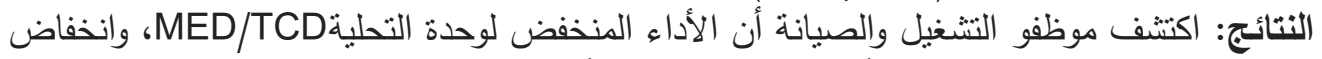

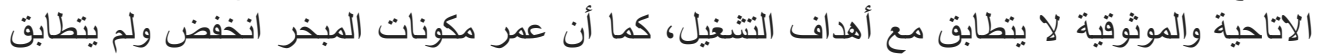

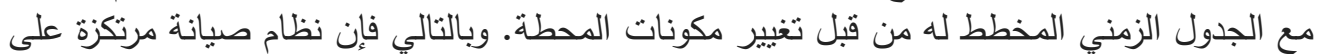



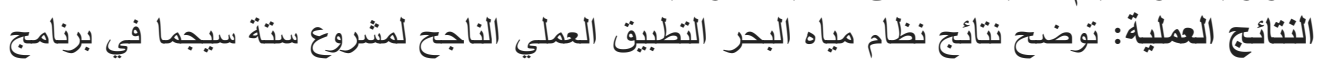
الصيانة لوحدة تحلية المياه من النوع تحلية متعددة التأثير / تقطير بالضغط النيط الحراري (MED/TCD).



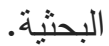

الكلمات الدالة: ستة سيجما- تحلية متعددة التأثير - تقطير بالضغط الحراري- نظام مياه البحر صيانة مرتكزة على الموثوقية- دورة (خطط- نفذ- تحقق - اتخذ قرار ) - الموثوقية- الاتاحية. 